\title{
Recurrence Kinetics after Laparoscopic Versus Open Surgery in Colon Cancer. A Meta-Analysis
}

\author{
Ross Lilley ${ }^{1}{ }^{1}$, Evangeline Chan ${ }^{1, \dagger}$, Nicklaus $\mathrm{Ng}^{1,+}$, Amber Orr ${ }^{1,+}$, Marcin Szostok ${ }^{1,+} \oplus$,

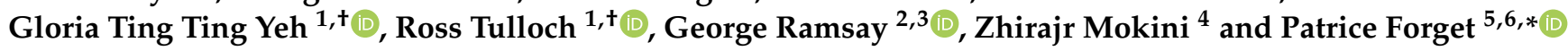 \\ 1 Institute of Applied Health Sciences, University of Aberdeen, Aberdeen AB25 2ZD, UK; \\ ross.lilley.17@abdn.ac.uk (R.L.); evangeline.chan.17@abdn.ac.uk (E.C.); nicklaus.ng.17@abdn.ac.uk (N.N.); \\ amber.orr.17@abdn.ac.uk (A.O.); marcin.szostok.17@abdn.ac.uk (M.S.); t.t.yeh.17@abdn.ac.uk (G.T.T.Y.); \\ ross.tulloch.17@abdn.ac.uk (R.T.) \\ 2 Rowett Institute of Nutrition and Health, University of Aberdeen, Aberdeen AB25 2ZD, UK; \\ george.ramsay@abdn.ac.uk \\ 3 Department of General Surgery, NHS Grampian, Aberdeen AB25 2ZN, UK \\ 4 Independent Researcher, supported by the European Society of Anaesthesiology and Intensive Care \\ Mentorship Programme, B-1000 Brussels, Belgium; zhirajrmokini@yahoo.com \\ 5 Epidemiology Group, Institute of Applied Health Sciences, School of Medicine, Medical Sciences and \\ Nutrition, University of Aberdeen, Aberdeen AB25 2ZD, UK \\ 6 Department of Anaesthesia, NHS Grampian, Aberdeen AB25 2ZN, UK \\ * Correspondence: forgetpatrice@yahoo.fr \\ + Equally contributors.
}

Citation: Lilley, R.; Chan, E.; Ng, N.; Orr, A.; Szostok, M.; Yeh, G.T.T.; Tulloch, R.; Ramsay, G.; Mokini, Z.; Forget, P. Recurrence Kinetics after Laparoscopic Versus Open Surgery in Colon Cancer. A Meta-Analysis. J. Clin. Med. 2021, 10, 4163. https:// doi.org/10.3390/jcm10184163

Academic Editor: Stanley W. Ashley

Received: 23 August 2021

Accepted: 10 September 2021

Published: 15 September 2021

Publisher's Note: MDPI stays neutral with regard to jurisdictional claims in published maps and institutional affiliations.

Copyright: (c) 2021 by the authors. Licensee MDPI, Basel, Switzerland. This article is an open access article distributed under the terms and conditions of the Creative Commons Attribution (CC BY) license (https:/ / creativecommons.org/licenses/by/ $4.0 /)$.
Abstract: Background: Colorectal cancer (CRC) is a leading cause of mortality worldwide and in the UK. Surgical resection is the main curative treatment modality available and using a laparoscopic vs. an open approach may have a direct influence on the inflammatory response, influencing cancer biology and potentially the recurrence kinetics by promoting cancer growth. Methods: This systematic review aims to compare laparoscopic with open surgery for the treatment of colon cancer with a specific focus on the moment of the recurrence. We included randomised controlled trials in intended curative surgery for colon cancer in adults. Interventions: Studies investigating laparoscopic vs. open resection as an intended curative treatment for patients with confirmed carcinoma of the colon. The two co-primary outcomes were the time to recurrence and the overall survival (OS) and disease-free survival (DFS) at three and five years. Meta-analyses were done on the mean differences. Results: After selection, we reviewed ten randomised controlled trials. Most of the trials did not display a statistically significant difference in either DFS or OS at three or at five years when comparing laparoscopic to open surgery. Groups did not differ for the OS and DFS, especially regarding the time needed to observe the median recurrence rate. The quality of evidence (GRADE) was moderate to very low. Conclusion: We observed no difference in the recurrence kinetics, OS or DFS at three or five years when comparing laparoscopic to open surgery in colon cancer.

Keywords: recurrence kinetics; laparoscopic surgery; open surgery; colon cancer; meta-analysis

\section{Introduction}

Colorectal cancer (CRC) is defined as cancer arising from the epithelium of the colon or rectum [1]. According to Cancer Research UK [2], it is the 4th most common cancer in the UK, constituting $11 \%$ of all new cancer diagnoses. It is also the second most common cause of cancer mortality in the UK. Survival is linked to stage at presentation: with early disease detection associated with better outcomes [3].

CRC is thought to have a multifactorial aetiology, with genetic factors, environmental exposures (diet, smoking and alcohol intake) and inflammatory conditions being implemented in its development [4]. Among the inflammatory condition, surgery is a scheduled one, and the reaction of tissue injury might be dependent on modifiable factors, like the 
surgical approach. Indeed, surgery is the most common treatment offered and sometimes considered to be the only curative modality [4]. Resection is often performed to remove the primary tumour [5] and can be done using different techniques, ranging from hemicolectomy, where one half of the colon is removed, to total colectomy, where the entire colon is removed [6]. Resection can be performed using different approaches, namely open or through a minimally invasive technique [7]. The open approach is the conventional method, but it is associated with more postoperative pain, a longer hospital stay and, importantly, a bigger inflammatory response which could, in turn, influence negatively the recurrence kinetics by promoting cancer growth [8]. In this context, separating the colon from rectal surgery is relevant. The disease is not only different in the rectum (treated with different neoadjuvant therapies for colon cancer), but the surgical approaches are also different. Laparoscopic hemicolectomy is a very different procedure from previous laparoscopic resections, but also includes specific challenges (and their inflammatory complications) with the rectum being in the pelvis.

\section{Aims and Objectives}

Many systematic reviews do not distinguish between colon and rectal cancer, with little specific data on colon cancer. This paper aims to conduct a systematic review with meta-analysis, using available literature on randomised controlled trials (RCTs) across multiple databases, to compare the effectiveness of laparoscopic versus open surgery for the intended curative resection of colon cancer in adults. The primary outcomes analysed are overall survival (OS) and disease-free survival (DFS) at both three and five years. The secondary objective is the comparison of the time to median recurrence rate.

\section{Materials and Methods}

\subsection{Inclusion and Exclusion Criteria}

We established the inclusion and exclusion criteria using the PICOS tool [9], which aided to focus our question. Table 1 summarises the research criteria.

Table 1. Inclusion and exclusion criteria used in the literature search.

\begin{tabular}{|c|c|c|}
\hline Patients & $\begin{array}{l}\text { Adult population }>18 \text { years } \\
\text { Colon cancer (all stages) }\end{array}$ & $\begin{array}{l}\text { Paediatrics }<18 \text { years } \\
\text { Metastatic disease } \\
\text { Rectal cancer }\end{array}$ \\
\hline Intervention & $\begin{array}{l}\text { Intended curative laparoscopic } \\
\text { surgery of primary tumour }\end{array}$ & \\
\hline Control & $\begin{array}{l}\text { Intended curative open surgery of } \\
\text { primary tumour }\end{array}$ & \\
\hline Outcomes & $\begin{array}{l}\text { 3-year disease-free survival } \\
\text { 3-year overall survival } \\
\text { 5-year disease-free survival } \\
\text { 5-year overall survival } \\
\text { Survival period } \\
\text { Disease-free period }\end{array}$ & \\
\hline Study Design & $\begin{array}{l}\text { Randomised controlled trials } \\
\text { published in English }\end{array}$ & All other study types \\
\hline
\end{tabular}

\subsection{Search Strategy}

We conducted literature search on Ovid MedLine, Ovid Embase, Cochrane Central Register of Controlled Trials and PubMed. Supplementary S1 reflects the search terms, combinations and applied limits used.

Two investigators assessed independently each database and compared the screening. This helped to ensure consistency and eradicate possible bias. After initial screening and removal of duplicates we compiled a final list of publications for review, as displayed in Figure 1. This search methodology is based on the PRISMA (Preferred Reporting Items of Systematic reviews and Meta-Analyses) flowchart. 


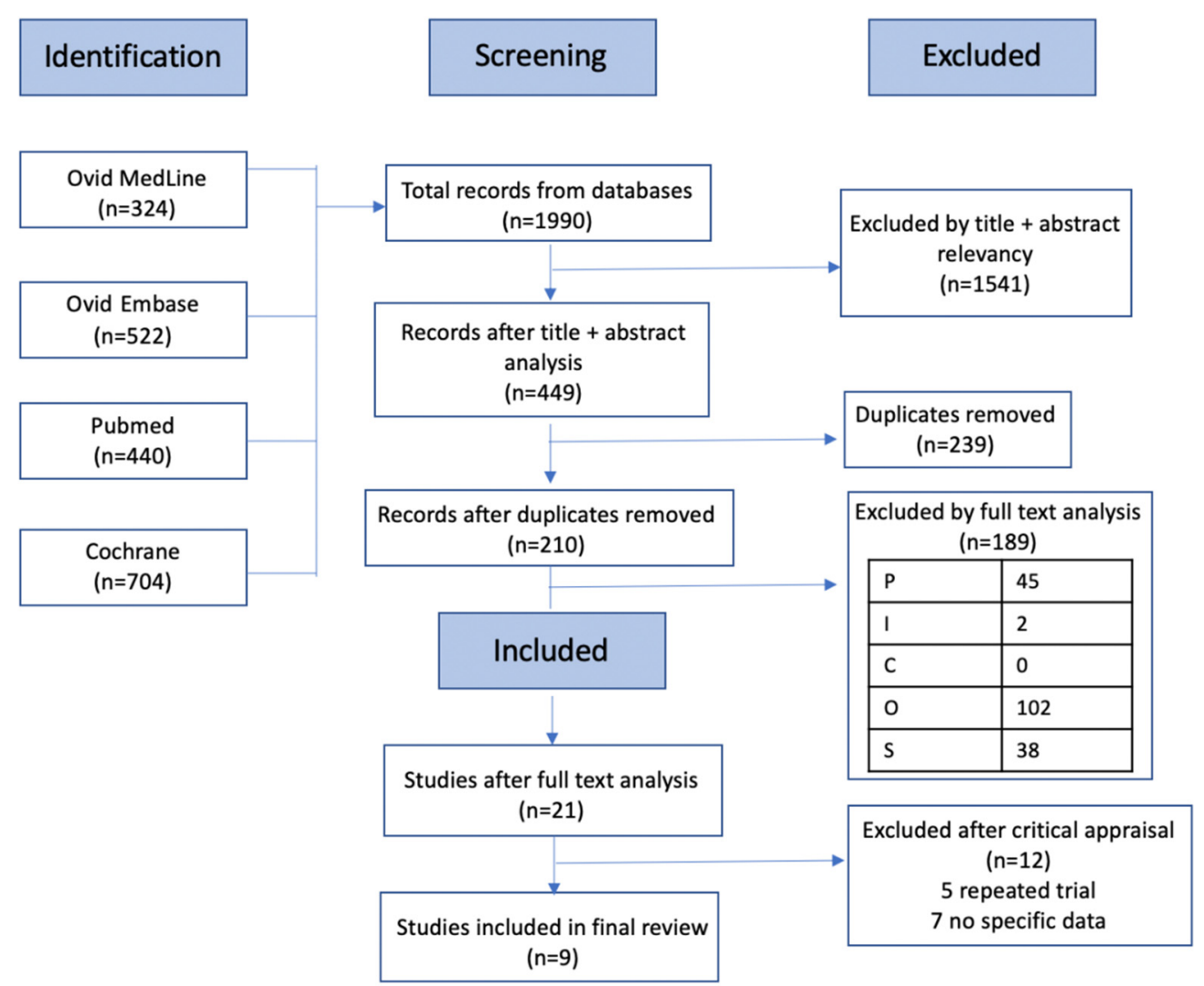

Figure 1. Flow diagram displaying literature search protocol. Adapted from PRISMA 2009 flow diagram [10].

\subsection{Data Collection and Analysis}

Two independent investigators extracted data from selected articles [11-20] and the research group verified it by using an independently created data extraction form (Supplementary S2). In one case we found a second publication from the same trial concerning colorectal cancer being published including only data for left colon cancer. When it was not possible to obtain the raw data from the authors, we extracted data from the figures using GetData Digitizer software V 2.26.0.20 (GetData Graph digitizer software version 2.25) assuming a normal distribution for the data [21] to perform the meta-analysis. We verified the accuracy and the precision of the tool across the graphs used and found the worst result of $+/-0.69 \%$ in Tung et al. [11].

We performed a group discussion to resolve discrepancies and compile data. To determine the quality of evidence extracted from all included studies for which $p$-values were available we used the GRADE approach [22]. As all studies were RCTs, the evidence in all cases was initially deemed 'high quality'. For serious limitations in study design or risk of bias we downgraded the quality of evidence by one level (or by two for very serious). In case of unexplained inconsistency, indirectness of evidence, imprecision of results or high probability of publication bias, we downgraded evidence by a further level [23].

We compared the mean survival and disease-free periods between groups. We computed quartiles and calculated the interquartile range. The interquartile range (IQR) divided by 1.35 is a robust measure that describes statistic dispersion and can serve as a surrogate of standard deviation [24].

We performed a meta-analysis for comparison of means for continuous data using RevMan V. 5.4.1 software (Cochrance Collaboration, Copenhagen, Denmark). Given the heterogeneity of studies we used the random effect method. 


\subsection{Critical Appraisal}

Two independent reviewers performed a critical appraisal for each paper, using a checklist developed by Scottish Intercollegiate Guidelines Network (SIGN) [25], to evaluate the validity of RCTs and their results. All members performed an appraisal at least twice. Table S1 shows the characteristics of each study.

\section{Results}

\subsection{Study Characteristics}

The literature search produced 1990 articles. Following title and abstract screening and full-text review, with inclusion and exclusion criteria applied, we identified a total of ten RCTs [11-20] for inclusion. No trial carried out any blinding procedure due to the nature of the surgical procedures. Three trials were multi-centre $[15,16,19]$, and seven single-centre $[11-14,17,18,20]$. Analysis involved in total 3610 colon cancer patients. Total of 1808 patients underwent laparoscopic surgery and 1802 underwent conventional open surgery for intended curative resection of a primary tumour. Three trials $[15,16,19]$ assessed the non-inferiority of laparoscopic compared to open resection, the remaining seven trials $[11-14,17,18,20]$ aimed to assess superiority. Almost all studies included data on both DFS and OS; the exception being Chung et al. [14] that measured only OS.

\subsection{Population}

All selected studies investigated laparoscopic vs. open resection as an intended curative treatment for patients with confirmed carcinoma of the colon. The age ranges for participants included: no limit [18], $\geq 18$ years [11-15,19], $\geq 20$ years [16,20] and $\geq 75$ years [17] Table 2 summarises the differences in tumour location. Stage of colon cancer differed between individuals in all studies and ranged from T0 to T4. However, separation of outcomes for each stage was beyond the scope of this review. Recurrent exclusion factors that we included were metastatic disease, pregnant or lactating women and patients considered unfit for surgery. The conduction of RCTs involved many countries, including Hong Kong, Japan, the USA and several European countries. All studies involved surgeons with adequate training to perform laparoscopic surgery.

\subsection{Intervention}

All included studies in this review assessed the use of non-robotic, laparoscopic resection of the colon with curative intent, with Chung et al. [14] using a hand-assisted technique. The only study to use a co-intervention was Tung et al., [11] who assessed the efficacy of endoscopically inserted, metal stents prior to laparoscopic resection of cancer obstructing the left colon. Nine studies $[11-17,19,20]$ reported the use of adjuvant chemotherapy in a proportion of participants. The chemotherapy agent varied between studies and included oral 5-fluorouracil derivatives, [16,17] leucovorin, [16] FOLFOX regimen [12,13], fluoropyrimidine [20] and un-specified regimens $[11,14,15]$. The proportion of patients receiving chemotherapy was balanced in intervention and comparator groups [19] in all studies. Three trials $[15,16,20]$ specified that adjuvant chemotherapy was administered in stage III patients. Two studies $[14,18]$ reported only on right laparoscopic hemicolectomy and one [13] reported only on left laparoscopic hemicolectomy. The remainder of the studies $[11,15-17,19,20]$ included patients with varying tumour locations, which in turn governed the resection site. Toritani et al. [20] was the only study to report the use of complete mesocolic excision. Lymph node harvesting occurred during laparoscopic surgery in all studies. 


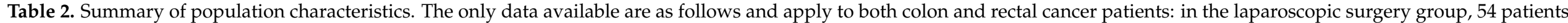
were $<80$ years and 44 were $\geq 80$ years. For open surgery, 53 were $<80$ years and 39 were $\geq 80$ years.

\begin{tabular}{|c|c|c|c|c|c|c|c|c|c|c|}
\hline \multirow{2}{*}{ Study } & \multirow{2}{*}{ Intervention } & \multirow{2}{*}{ Control } & \multirow{2}{*}{ Population } & \multicolumn{2}{|c|}{ Average Age (Year) } & \multicolumn{2}{|c|}{ Sample Size Analysed } & \multicolumn{2}{|c|}{ Male Sex $(\%)$} & \multirow[b]{2}{*}{$95 \% \mathrm{CI}$} \\
\hline & & & & Laparoscopic & Open Resection & Laparoscopic & Open Resection & Laparoscopic & Open Resection & \\
\hline Braga et al., 2005 & Laparoscopic surgery & Open surgery & $\begin{array}{c}\geq 18 \text { years } \\
\text { Colorectal cancer }\end{array}$ & 65 (13) mean (SD) & 67 (11) mean (SD) & 190 & 201 & 60 & 60 & $-14.70[-18.04,-11.36]$ \\
\hline Braga et al., 2010 & Laparoscopic surgery & Open surgery & $\begin{array}{c}\geq 18 \text { years } \\
\text { Carcinoma of left colon }\end{array}$ & $62.9^{\dagger}$ & $64.9^{+}$ & 78 & 89 & $51^{+}$ & $53^{+}$ & \\
\hline Chung et al., 2007 & Hand-assisted laparoscopic colectomy & Open colectomy & $\begin{array}{c}\geq 18 \text { years } \\
\text { Carcinoma of cecum or ascending colon }\end{array}$ & 71 & 72.5 & 41 & 40 & 61 & 65 & $21.00[6.42,35.58]$ \\
\hline COLOR, 2009 & Laparoscopic surgery & Open resection & $\begin{array}{l}\geq 18 \text { years } \\
\text { Carcinoma of caecum, ascending colon, } \\
\text { descending colon or sigmoid colon }\end{array}$ & 71 & 71 & 534 & 542 & 52 & 53 & $-5.80[-9.56,-2.04]$ \\
\hline $\operatorname{COST}, 2007$ & Laparoscopically assisted colectomy & Open colectomy & $\begin{array}{c}\geq 18 \text { years } \\
\text { Carcinoma of right, left or sigmoid colon }\end{array}$ & 70 & 69 & 435 & 428 & 51 & 49 & $3.90[-1.66,9.46]$ \\
\hline Ishibe et al, 2017 & $\begin{array}{c}\text { Minimally invasive } \\
\text { laparoscopic resection }\end{array}$ & $\begin{array}{c}\text { Conventional open } \\
\text { resection }\end{array}$ & $\begin{array}{l}\geq 75 \text { years } \\
\text { Adenocarcinoma of colon and rectum }\end{array}$ & $\mathrm{NI}$ & $\mathrm{NI}$ & 69 & 63 & 50 & 60 & $-5.60[-13.52,2.32]$ \\
\hline JCOG404, 2017 & Laparoscopic surgery & Open surgery & $\begin{array}{c}20-75 \text { years } \\
\text { Carcinoma of caecum, ascending colon, } \\
\text { sigmoid colon }\end{array}$ & 64 & 64 & 525 & 520 & 54 & 60 & $4.90[0.64,9.16]$ \\
\hline Li et al., 2012 & $\begin{array}{l}\text { Laparoscopic assisted } \\
\text { right hemicolectomy }\end{array}$ & $\begin{array}{l}\text { Open right } \\
\text { hemicolectomy }\end{array}$ & $\begin{array}{l}\text { All ages } \ddagger \\
\text { carcinomas of caecum, ascending colon, } \\
\text { hepatic flexure or transverse colon }\end{array}$ & 68 & 68 & 71 & 74 & 46 & 43 & $-14.80[-41.27,11.67]$ \\
\hline Toritani et al., 2019 & Laparoscopic surgery & $\begin{array}{c}\text { Conventional open } \\
\text { surgery }\end{array}$ & $\begin{array}{c}\geq 20 \text { years } \\
\text { Transverse and descending colon cancer }\end{array}$ & 64 & 67 & 33 & 33 & 73 & 48 & \\
\hline Tung et al., 2013 & Endolaparoscopic resection & $\begin{array}{l}\text { Conventional open } \\
\text { surgery }\end{array}$ & $\begin{array}{l}\geq 18 \text { years } \\
\text { Obstructed left sided colon cancer. }\end{array}$ & 64.5 & 68.5 & 22 & 13 & 58 & 50 & $-1.30[-17.69,15.09]$ \\
\hline
\end{tabular}

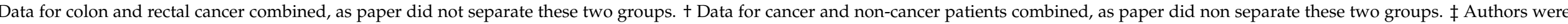

contacted to confirm that all the participants were over 18 years old in accordance with the inclusion criteria of this review, refer to Table S1. 


\subsection{Comparator}

Conventional open resection of colon cancer with curative intent acted as a control in all studies. The only study to compare a laparoscopic intervention to emergency laparotomy was Tung et al. [11] in colonic obstruction. As with the laparoscopic group, two studies $[14,18]$ reported on right hemicolectomy and one study [13] reported on left hemicolectomy in control groups. In the other six studies [11,15-17,19,20], the section of colon resected reflected tumour location. Toritani et al. [20] reported the use of complete mesocolic excision in both groups. Lymph node harvesting was performed during open surgery in all studies.

\subsection{Outcomes}

\subsubsection{Overall Survival}

All studies provided data for OS (Table 3). Two studies listed OS as their primary outcome [11,16], and eight considered it as a secondary outcome [12-15,17-20]. The trials reported results at various follow-up times. Braga et al. [12,13] only published 5-year survival results. Conversely, Ishibe et al. [17] only provided 3-year survival results. Six studies $[11,14-16,18,20]$ reported 5-year OS. The COLOR trial [19] was the only study to state both 3- and 5-year OS clearly in their paper. After a follow-up of three years, two studies $[17,19]$ reported OS which was not different (i.e., $p>0.05$ ). At 5-year follow-up, six studies $[11,13-15,18,20]$ did not find any statistical significance in OS between the laparoscopic and open resection groups. Meta-analysis revealed no difference between groups in the survival periods (Figure 2).

\subsubsection{Disease-Free Survival}

DFS was a primary outcome in three studies $[11,15,19]$ and as a secondary outcome in seven (Table 4) [12-14,16-18,20]. Chung et al. [14] did not provide any data on this outcome. Follow-up periods for the reported values varied between studies. Braga et al. [12,13] provided no data on 3-year DFS. Conversely, Ishibe et al. [17] provided no data regarding 5-year DFS. Five other studies $[11,15,16,18,20]$ reported 5-year DFS in their report without explicitly stating data on 3-year DFS; in these five studies, we extracted manually the values for 3-year DFS from Kaplan-Meier curves. Only the COLOR trial [19] stated the values for both 3- and 5-year DFS directly in their report. Ishibe et al. [17] was the only study to find no statistically significant difference in 3-year DFS between the two arms of their study. The COLOR trial [19] suggested that laparoscopic surgery was clinically non-inferior to open colectomy. At 5-years follow-up, six studies [11-13,15,18,20] found no significant difference between the laparoscopic and open groups. The results of two of these studies, Braga et al. [13] and Li et al. [17] excluded patients with stage IV disease. Meta-analysis revealed no difference between groups in the disease-free periods (Figure 3). 


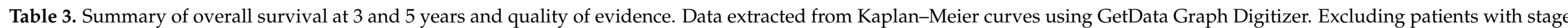
IV disease.

\begin{tabular}{|c|c|c|c|c|c|c|c|c|c|c|c|c|c|c|c|c|}
\hline \multirow{2}{*}{$\begin{array}{c}\text { Overall Survival } \\
\text { Study }\end{array}$} & \multicolumn{3}{|c|}{ 3-Year Follow-Up (\%) } & \multicolumn{3}{|c|}{ 5-Year Follow-Up (\%) } & \multicolumn{3}{|c|}{ LPS } & \multicolumn{3}{|c|}{ LPT } & \multirow[b]{2}{*}{ Weight } & \multirow[b]{2}{*}{$95 \%$ CI } & \multirow[b]{2}{*}{$\begin{array}{c}\text { Quality of Evidence } \\
\text { (GRADE) }\end{array}$} & \multirow[b]{2}{*}{ Comments } \\
\hline & LPS & LPT & $p$ & LPS & LPT & $p$ & Mean & SD & Patients & Mean & SD & Patients & & & & \\
\hline Li 2012 & 83.4 & 86.1 & $\mathrm{NA}$ & 74.2 & 75.0 & 0.835 & 43.2 & 99.9 & 71 & 58.0 & 55.6 & 74 & $5.2 \%$ & $-14.80[-41.27,11.67]$ & 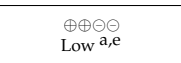 & $\begin{array}{l}\text { There may have been no difference in 5-year OS between } \\
\text { laparoscopic and open surgery. }\end{array}$ \\
\hline Braga 2005 & $\mathrm{NI}$ & $\mathrm{NI}$ & $\mathrm{NA}$ & 72 & 66 & 0.321 & 13.9 & 6.6 & 190 & 28.6 & 23.175 & 201 & $15.8 \%$ & $\left.\begin{array}{c}-14.70 \\
{[-18.04,-11.36]}\end{array}\right]$ & 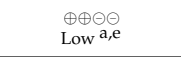 & $\begin{array}{l}\text { There may have been no difference in } 5 \text {-year OS between } \\
\text { laparoscopic and open surgery. }\end{array}$ \\
\hline Braga 2010 & $\mathrm{NI}$ & $\mathrm{NI}$ & $\mathrm{NA}$ & 61.1 & 56.5 & $\begin{array}{c}0.16-0.65 \\
\text { according to stage }\end{array}$ & $\mathrm{NA}$ & $\mathrm{NA}$ & $\mathrm{NA}$ & $\mathrm{NA}$ & $\mathrm{NA}$ & $\mathrm{NA}$ & 0 & Not estimable & $\begin{array}{l}\oplus \oplus \oplus \ominus \\
\text { Low } \mathrm{a}, \mathrm{e}\end{array}$ & $\begin{array}{l}\text { There may have been no difference in 5-year OS between } \\
\text { laparoscopic and open surgery. }\end{array}$ \\
\hline COLOR 2009 & 81.8 & 84.2 & 0.45 & 73.8 & 74.2 & $\mathrm{NI}$ & 25.7 & 27.3 & 534 & 31.5 & 35.2 & 542 & $15.7 \%$ & $-5.80[-9.56,-2.04]$ & $\begin{array}{r}\oplus \oplus \oplus \ominus \ominus \\
\text { Moderate }^{\mathrm{a}} \\
\end{array}$ & $\begin{array}{l}\text { There is probably no difference in 3-year OS after laparoscopic } \\
\text { surgery compared to open surgery. }\end{array}$ \\
\hline Ishibe 2017 & 93.9 & 93.5 & 0.901 & NI & $\mathrm{NI}$ & $\mathrm{NA}$ & 19.7 & 13.4 & 69 & 25.3 & 29.4 & 63 & $13.8 \%$ & $-5.60[-13.52,2.32]$ & $\underset{\text { Moderate }}{\oplus \oplus \oplus \ominus \mathrm{a}}$ & $\begin{array}{l}\text { There is probably no difference in } 5 \text {-year } O \text { after laparoscopic } \\
\text { surgery compared to open surgery. }\end{array}$ \\
\hline Tung 2013 & 71 & 46 & $\mathrm{NA}$ & 48 & 27 & 0.076 & 29.0 & 23.9 & 22 & 30.3 & 23.9 & 13 & $9.0 \%$ & $-1.30[-17.69,15.09]$ & $\begin{array}{c}\oplus \ominus \ominus \ominus, \mathrm{b}, \mathrm{e} \\
\text { Very Low } \mathrm{b}, \mathrm{e}\end{array}$ & $\begin{array}{l}\text { There may have been no difference in 3-year OS after laparoscopic } \\
\text { compared to open surgery, but the evidence is uncertain. }\end{array}$ \\
\hline Toritani 2019 & 97.1 & 100.0 & $\mathrm{NA}$ & 93.3 & 100.0 & 0.543 & 55.5 & 26.2 & 33 & 0.0 & 0.0 & 33 & 0 & Not estimable & $\begin{array}{l}\oplus \oplus \oplus \ominus \\
\text { Low }^{\mathrm{a}, \mathrm{e}}\end{array}$ & $\begin{array}{l}\text { 5-year OS after Laparoscopic surgery may not have been } \\
\text { non-inferior to open surgery. }\end{array}$ \\
\hline COST 2007 & 86.8 & 86.8 & $\mathrm{NA}$ & 76.4 & 74.6 & 0.93 & 50.1 & 42.76 & 435 & 46.2 & 40.6 & 428 & $15.0 \%$ & $3.90[-1.66,9.46]$ & $\underset{\text { Moderate }}{\oplus \oplus \oplus \ominus}$ & $\begin{array}{l}\text { There is probably no difference in 5-year OS after laparoscopic } \\
\text { surgery compared to open surgery. }\end{array}$ \\
\hline JCOG404 2017 & 96 & 95.8 & $\mathrm{NA}$ & 91.8 & 90.4 & $0.073+$ & 53.7 & 43.3 & 525 & 48.8 & 24.5 & 520 & $15.5 \%$ & $4.90[0.64,9.16]$ & 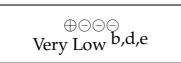 & $\begin{array}{l}\text { There may have been no difference in } 5 \text {-year OS after laparoscopic } \\
\text { compared to open surgery, but the evidence is uncertain. }\end{array}$ \\
\hline Chung 2007 & 95 & 86 & $\mathrm{NA}$ & 83 & 74 & 0.90 & 49.1 & 44.0 & 41 & 28.1 & 18.0 & 40 & $10.0 \%$ & $21.00[6.42,35.58]$ & $\begin{array}{l}\oplus \ominus \ominus \ominus \\
\text { Very Low } \mathrm{a}, \mathrm{d}, \mathrm{e}\end{array}$ & $\begin{array}{l}\text { There may have been no difference in } 5 \text {-year OS after laparoscopic } \\
\text { compared to open surgery, but the evidence is uncertain. }\end{array}$ \\
\hline
\end{tabular}

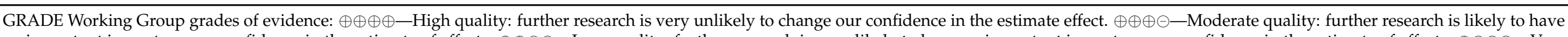

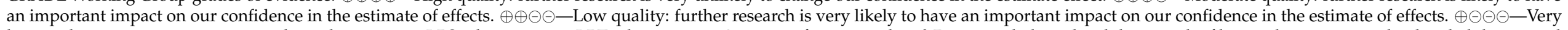

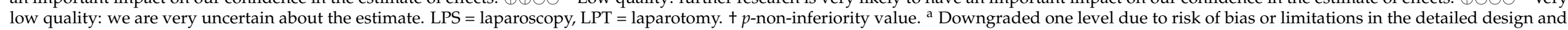

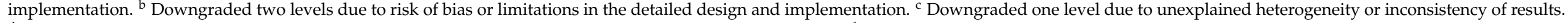

${ }^{d}$ Downgraded one level due to indirectness of evidence. ${ }^{e}$ Downgraded one level due to imprecision of results. ${ }^{f}$ Downgraded one level due to high probability of publication bias. 


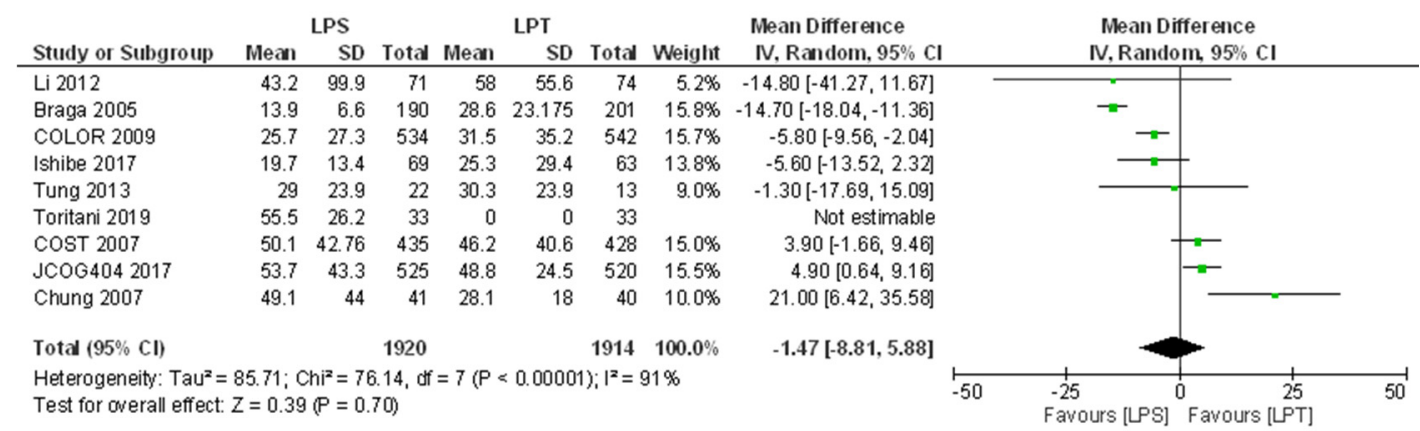

Figure 2. Forest plot of comparison: Mean difference for the overall survival. LPS: laparoscopic approach; LPT: open approach (laparotomy).

\subsubsection{Meta-Analysis}

Studies presented a high within-studies variance. As shown in Figures 2 and 3, at least $70 \%$ of the observed variance between studies is due to real differences in the effect size whereas less than $30 \%$ of the observed variance would have been expected based on random error.

\subsection{Bias Assessment \\ 3.6.1. Selection Bias}

All studies involved in this review used randomisation to limit baseline differences between the patient groups. (Table S2) Six [12-15,18-20] used computer-generated lists to reduce the risk of selection bias. The remaining four [14-17] did not detail how lists were generated. Five $[15-17,19,20]$ studies employed stratification to minimise imbalance between the size of the groups. Studies used tumour location or the proposed resection method as predominant variables. Braga et al., Chung et al., and Li et al., [12-14,18] noted the use of independent persons to deliver allocation information via sealed envelopes prior to surgery carries risks of bias [23]. The remaining six studies did not describe allocation concealment in sufficient detail for comment.

\subsubsection{Performance Bias}

Due to the surgical nature of the interventions, all studies had considerable performance bias, hence a high risk for overall bias. Further, five studies $[12,13,16,17,20]$ noted adjuvant chemotherapy provision for some participants.

\subsubsection{Detection Bias}

None of the studies provided information on the assessors used in follow-up. However, failure to pick up recurrence might have affected DFS.

\subsubsection{Attrition Bias}

Two studies did not report attrition [14,20]. Five of the remaining papers $[12,13,15,17-19]$ reported low dropout rates in their studies of $5 \%$ or less. Two studies [11,16] reported dropout rates to be higher than 5\%-the JCGOG0404 trial, 16 which reported attrition of $6 \%$ and Tung et al., [11] which reported attrition of $27 \%$. Attrition rates of $20 \%$ or higher represent a high risk of attrition bias, and rates between $5 \%$ and $20 \%$ have a small risk of bias. [26] Therefore, there is a risk of attrition bias present in these two papers, although the risk of bias in the JCGOG0404 trial is low. Common reasons for attrition were metastatic disease at surgery leading to exclusion from the study and patients lost to follow-up. 


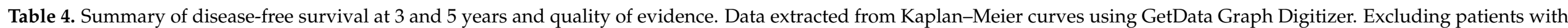
stage IV disease.

\begin{tabular}{|c|c|c|c|c|c|c|c|c|c|c|c|c|c|c|c|c|}
\hline \multirow{2}{*}{$\begin{array}{c}\text { Disease-Free Survival } \\
\text { Study }\end{array}$} & \multicolumn{3}{|c|}{ 3-Year Follow-Up (\%) } & \multicolumn{3}{|c|}{ 5-Year Follow-Up (\%) } & \multicolumn{3}{|c|}{ LPS } & \multicolumn{3}{|c|}{ LPT } & \multirow[b]{2}{*}{ Weight } & \multirow[b]{2}{*}{$95 \%$ CI } & \multirow[b]{2}{*}{$\begin{array}{l}\text { Quality of } \\
\text { Evidence (GRADE) }\end{array}$} & \multirow[b]{2}{*}{ Comments } \\
\hline & LPS & LPT & $p$ & LPS & LPT & $p$ & Mean & SD & Patients & Mean & SD & Patients & & & & \\
\hline Tung 2013 & 77 & 78 & $\mathrm{NA}$ & 52 & 48 & 0.63 & 38.7 & 28.5 & 22 & 45.7 & 24.8 & 13 & $1.7 \%$ & $-7.00[-24.99,10.99]$ & $\begin{array}{c}\oplus \oplus \ominus \ominus, \mathrm{a}, \mathrm{d} \\
\text { Very Low } \mathrm{a}, \mathrm{d}, \mathrm{e}\end{array}$ & $\begin{array}{l}\text { There may have been no difference in } 5 \text {-year DFF after laparoscopic } \\
\text { compared to open surgery but the evidence is uncertain. }\end{array}$ \\
\hline Li 2012 & 84.3 & 86.3 & NA & 82.3 & 84.1 & 0.78 & 14.4 & 20.1 & 71 & 20.6 & 12.8 & 74 & $10.7 \%$ & $-6.20[-11.71,-0.69]$ & 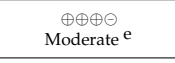 & $\begin{array}{l}\text { There is probably no difference in 5-year DFS after laparoscopic } \\
\text { surgery compared to open surgery. }\end{array}$ \\
\hline JCOG0404 2017 & 80.1 & 82 & $\mathrm{NA}$ & 80 & 79 & $\mathrm{NI}$ & 17.2 & 19.2 & 525 & 21.84 & 21.8 & 520 & $19.0 \%$ & $-4.64[-7.13,-2.15]$ & 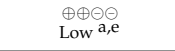 & NA \\
\hline Toritani 2019 & 90.5 & 87.2 & $\mathrm{NA}$ & 90.5 & 87.3 & 0.752 & 20.0 & 3.5 & 33 & 20.5 & 3.2 & 33 & $21.5 \%$ & $-0.50[-2.12,1.12]$ & $\begin{array}{r}\oplus \ominus \ominus \ominus, \\
\text { Very Low b,d,e }\end{array}$ & $\begin{array}{l}\text { There may have been no difference in 5-year DFS after laparoscopic } \\
\text { compared to open surgery but the evidence is uncertain. }\end{array}$ \\
\hline COLOR 2009 & 74.2 & 76.2 & $\begin{array}{r}0.70, \\
0.030^{+}\end{array}$ & 66.5 & 67.9 & NI & 20.3 & 26.1 & 534 & 19.1 & 23.3 & 542 & $17.6 \%$ & $1.20[-1.76,4.16]$ & 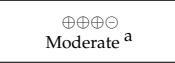 & $\begin{array}{l}\text { 3-year DFS after laparoscopic surgery is probably not non-inferior } \\
\text { to open surgery. }\end{array}$ \\
\hline Ishibe 2017 & 89.6 & 91.5 & 0.73 & $\mathrm{NI}$ & NI & NA & 13.7 & 13.6 & 69 & 11.6 & 18.8 & 63 & $10.4 \%$ & $2.10[-3.54,7.74]$ & $\begin{array}{c}\oplus \ominus \ominus \ominus, \mathrm{Q} \\
\text { Very Low } \mathrm{b}, \mathrm{d}, \mathrm{e}\end{array}$ & $\begin{array}{l}\text { There may have been no difference in 3-year DFS after laparoscopic } \\
\text { compared to open surgery but the evidence is uncertain. }\end{array}$ \\
\hline Braga 2005 & $\mathrm{NI}$ & NI & $\mathrm{NA}$ & 64.5 & 60.2 & $\begin{array}{c}0.55-0.81 \\
\text { according to stage }\end{array}$ & 21.3 & 26.2 & 190 & 18.2 & 34.34 & 201 & $9.7 \%$ & $3.10[-2.93,9.13]$ & $\begin{array}{l}\oplus \oplus \ominus \ominus \\
\text { Low } \mathrm{a}, \mathrm{e} \\
\end{array}$ & $\begin{array}{l}\text { There may have been no difference in } 5 \text {-year DFS between } \\
\text { laparoscopic and open surgery. }\end{array}$ \\
\hline Braga 2010 & $\mathrm{NI}$ & NI & $\mathrm{NA}$ & 63 & 63 & 0.405 & $\mathrm{NA}$ & $\mathrm{NA}$ & $\mathrm{NA}$ & $\mathrm{NA}$ & $\mathrm{NA}$ & NA & 0 & Not estimable & 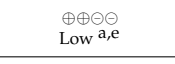 & $\begin{array}{l}\text { There may have been no difference in } 5 \text {-year DFS between } \\
\text { laparoscopic and open surgery. }\end{array}$ \\
\hline COST 2007 & 80.4 & 79.2 & $\mathrm{NA}$ & 69.2 & 68.4 & 0.94 & 36.4 & 47.9 & 435 & 32.0 & 44.0 & 428 & $9.5 \%$ & $4.40[-1.73,10.53]$ & 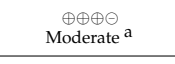 & $\begin{array}{l}\text { There is probably no difference in } 5 \text {-year DFS after laparoscopic } \\
\text { surgery compared to open surgery. }\end{array}$ \\
\hline Chung 2007 & NI & $\mathrm{NI}$ & $\mathrm{NA}$ & $\mathrm{NI}$ & NI & NA & $\mathrm{NA}$ & NA & $\mathrm{NA}$ & $\mathrm{NA}$ & $\mathrm{NA}$ & NA & 0 & Not estimable & 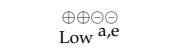 & $\mathrm{N} / \mathrm{A}$ \\
\hline
\end{tabular}

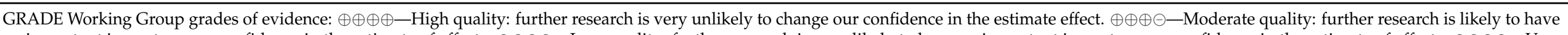

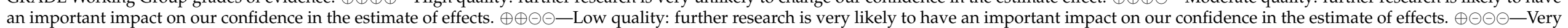

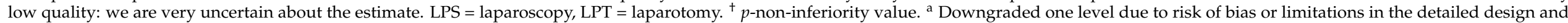

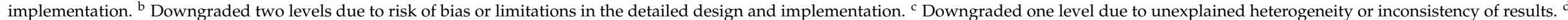
Downgraded one level due to indirectness of evidence. ${ }^{\mathrm{e}}$ Downgraded one level due to imprecision of results. ${ }^{\mathrm{f}}$ Downgraded one level due to high probability of publication bias. 


\begin{tabular}{|c|c|c|c|c|c|c|c|c|c|c|c|}
\hline \multirow[b]{2}{*}{ Study or Subgroup } & \multicolumn{3}{|c|}{ LPS } & \multicolumn{3}{|c|}{ LPT } & \multicolumn{2}{|r|}{ Mean Difference } & \multirow{2}{*}{\multicolumn{3}{|c|}{$\begin{array}{l}\text { Mean Difference } \\
\text { IV, Random, } 95 \% \mathrm{Cl}\end{array}$}} \\
\hline & Mean & SD & Total & Mean & SD & Total & Weight & IV, Random, $95 \% \mathrm{Cl}$ & & & \\
\hline Tung 2013 & 38.7 & 28.5 & 22 & 45.7 & 24.8 & 13 & $1.7 \%$ & $-7.00[-24.99,10.99]$ & & & \\
\hline Li 2012 & 14.4 & 20.1 & 71 & 20.6 & 12.8 & 74 & $10.7 \%$ & $-6.20[-11.71,-0.69]$ & - & & \\
\hline$J C O G 4042017$ & 17.2 & 19.2 & 525 & 21.84 & 21.8 & 520 & $19.0 \%$ & $-4.64[-7.13,-2.15]$ & 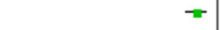 & & \\
\hline Toritani 2019 & 20 & 3.5 & 33 & 20.5 & 3.2 & 33 & $21.5 \%$ & $-0.50[-2.12,1.12]$ & & & \\
\hline Chung 2007 & 0 & 0 & 0 & 0 & 0 & 0 & & Not estimable & & & \\
\hline COLOR 2009 & 20.3 & 26.1 & 534 & 19.1 & 23.3 & 542 & $17.6 \%$ & $1.20[-1.76,4.16]$ & & - & \\
\hline Ishibe 2017 & 13.7 & 13.6 & 69 & 11.6 & 18.8 & 63 & $10.4 \%$ & $2.10[-3.54,7.74]$ & & - & \\
\hline Braga 2005 & 21.3 & 26.2 & 190 & 18.2 & 34.34 & 201 & $9.7 \%$ & $3.10[-2.93,9.13]$ & & - & \\
\hline COST 2007 & 36.4 & 47.9 & 435 & 32 & 44 & 428 & $9.5 \%$ & $4.40[-1.73,10.53]$ & & & \\
\hline Total $(95 \% \mathrm{Cl})$ & & & 1879 & & & 1874 & $100.0 \%$ & $-0.63[-3.06,1.81]$ & & & \\
\hline $\begin{array}{l}\text { Heterogeneity: } \mathrm{Tau}^{2} \\
\text { Test for owerall effect }\end{array}$ & $\begin{array}{l}6.52 ; \mathrm{Cl} \\
Z=0.50\end{array}$ & $\begin{array}{l}h^{2}=20 \\
(P=0\end{array}$ & $\begin{array}{l}0.45, \mathrm{df} \\
.61)\end{array}$ & $=7(\mathrm{P}=$ & $=0.005)$ & $I^{2}=66$ & & & $\begin{array}{l}-25 \\
\text { Favours [LPS] }\end{array}$ & ${ }^{0}$ Favours [ᄂ? & $\begin{array}{l}25 \\
\text { PT] }\end{array}$ \\
\hline
\end{tabular}

Figure 3. Forest plot of comparison: Mean difference for the disease-free survival. LPS: laparoscopic approach; LPT: open approach (laparotomy).

\subsubsection{Reporting Bias}

No paper reported any conflicts of interest. Seven reported no external funding. The COST trial received a number of grants from the National Cancer Institute [15] and the COLOR trial received funding from Ethicon Endo-surgery and the Swedish Cancer Foundation [19]. Neither corporation influenced initiation, design or any other aspect of the study.

\section{Discussion}

We evaluated OS, DFS and recurrence kinetics after laparoscopic vs. open surgical approach for colon cancer resection. There is probably no difference in these outcomes (moderate to very low level of certainty). As there is uncertain evidence about the differences in the inflammatory response after laparoscopy vs. laparotomy for colon cancer, we cannot formally conclude on the absence of effect of inflammatory processes on the outcome. However, we can reasonably conclude that the effect of the surgical approach on the inflammatory response, if any, is probably not sufficient to influence these outcomes.

Increased inflammation or immunosuppression caused by surgical technique may favour cancer proliferation after surgery, depending on the type of inflammatory mediators produced $[27,28]$. However most studies come from often small laboratory experiments or trials, while what happens in the human body is incredibly more complex [29]. Here, we evaluated OS and DFS after laparoscopic vs. open approach for colon cancer resection.

All included papers discussed these outcomes. Four trials $[11,15,16,19]$ had eitheror both outcomes as their primary endpoint, and six $[12-14,17,18,20]$ had them as part of their secondary endpoint. Both outcomes were further split into 3-year OS/DFS, and 5-year OS/DFS.

Due to colon cancer's potential to progress into a higher-grade cancer, it was difficult for the patients recruited to have open surgery or laparoscopic surgery as their sole intervention throughout the study. The JCOG0404 trial [16] randomly assigned 1057 patients at the beginning to two treatment arms: laparoscopic resection and open resection. However, of the 520 that had open surgery, $174(33.5 \%)$ had adjuvant chemotherapy, and of the 525 that had laparoscopic surgery, 199 (37.9\%) underwent adjuvant chemotherapy. These patients, however, were included with patients that did not undergo this additional treatment. Thus, as the adjuvant chemotherapy could have been a confounding factor, data for survival outcomes may have been affected. This confounder was also present in the trial by Braga et al., [12] where adjuvant chemotherapy was given to $118(62.1 \%)$ patients in the laparoscopic surgery arm, and $124(61.6 \%)$ patients in the open surgery arm, the COLOR trial [19] and Toritani et al. [20]. In addition, the majority of papers $[12,13,16,17,20]$ did not report on the chemotherapy regime or length of treatment. No papers mentioned the dosage of chemotherapy given to the patients. These factors may have greatly affected outcomes but also open a new avenue of research on the need to consider the perioper- 
ative management (and treatments) of cancer as a whole in patients (before, during and after surgery).

There were some inconsistencies regarding patient cohort characteristics across the trials. Ishibe et al. [17] recruited patients $>75$ years of age, Toritani et al. [20] recruited patients $>20$ years of age, the JCOG0404 trial [16] recruited patients from 20-75 years old, Tung et al. [11] did not mention the age group of their patients, and the other trials recruited patients $>18$ years. As Ishibe et al. [17] had produced data from a patient-population of the elderly, it may be inappropriate to compare this set of data to data from other trials studying patients of a wider age range. The presence of co-morbidities is more likely among elderly patients, which will influence the data on OS and DFS rates. Age, and potentially frailty, is particularly relevant to consider in the perioperative context but insufficient, and the limited sample size here precludes any specific conclusion on that [30-33].

\subsection{Quality of Evidence (GRADE)}

The quality of evidence ranged from moderate to very low across the studies included in this review. All studies, excluding Li et al., [18] were downgraded by at least one level as they were deemed high risk of bias according to the Cochrane RoB 2.0 tool (Cochrane Collaboration, Copenhagen, Denmark) [34]. This was mainly due to a lack of blinding in the surgical setting of the trials. Ishibe et al. [17] and Toritani et al. [20] were marked down by a further level due to risk of bias in the measurement of outcomes. The quality of evidence from Ishibe et al. [17] and Tung et al. [11] was further lowered due to indirectness of the population (elderly participants) and intervention (co-intervention with endoscopic stenting) respectively. Imprecision due to a lack of power towards survival outcomes lowered the quality of evidence in all six superiority trials and the JCOG0404 trial [16]. In the superiority trials, this was due to assessment of these outcomes as secondary outcomes. The JCOG0404 trial [16] authors aimed to power their trial to 5-year OS, but they failed to accrue an adequate number of participants to reach their intended power.

The meta-analysis carried out in this review included RCTs in the present systematic review, in particular, the COLOR trial [19]. Although this trial could not statistically prove non-inferiority, when combined with other studies in meta-analysis, no statistically significant difference between laparoscopic surgery and open surgery was seen. We recommend an updated meta-analysis looking at 3- and 5-year survival so that an assessment of effect sizes can be carried out with the inclusion of studies published since Di et al. [35].

\subsection{Limitations}

As mentioned, the quality of multiple studies used in this review were downgraded due to lack of blinding, concerns about outcome measurement, and indirectness of population and intervention. This brings to question the validity of the data analysed, as some may be inaccurate.

Data that were not directly reported in some studies, such as 3-year survival, were extracted from Kaplan-Meier graphs. The limitation of this is that p-values have not been calculated. However, it is reasonable to extrapolate 5-year confidence intervals to 3-year data, which would make these data more robust.

There were several studies in which data might possibly be unreliable due to its small sample size. Chung et al., [14] Tung et al., [11] and Toritani et al. [20] reported that the number of patients they had recruited and randomised into the trial was 81,48 and 66 respectively. Their sample sizes are significantly smaller than other trials analysed in this systematic review (COLOR trial [19] - 1248 patients, and JCOG040 trial [16] - 1057 patients). Trials with small sample sizes risk false-positive results and over-estimation of differences in outcomes [36-39]. In this case, any difference in outcomes between the laparoscopic and open surgery groups might appear to be overstated. Overall, this warrants further studies to reduce uncertainty. Other future human studies could include, for example, better staging of colon cancer patients allowing for more accurate stratification. 


\section{Conclusions}

This meta-analysis shows that laparoscopic surgery appears to have a similar outcome, and specifically similar recurrence dynamics, when compared to open surgery for the intended curative treatment of colon cancer in the adult population, in relations to OS and DFS at both three and five years. Future research is needed on other cancers or in patients with different profiles (metastatic diseases, specific conditions like advanced age or frailty) to study whether the same conclusion can be reached. Finally, we suggest considering as a whole the perioperative care and treatments of the cancer patients.

Supplementary Materials: The following are available online at https:/ /www.mdpi.com/article/ 10.3390/jcm10184163/s1, Supplementary S1: Databases and Search Strategies, Supplementary S2: Independently Developed Data Extraction Tool, Table S1: Summary of critical appraisals of selected studies, performed using the SIGN checklist [25], Table S2: Summary of Revised Cochrane Risk-of Bias Tool for Randomised Trials (RoB 2.0) [26].

Author Contributions: R.L.-searched and screened trials from Embase, critically appraised studies, developed data extraction tool, extracted data and assessed risk of bias of studies, GRADE assessment of all studies, results section of the report and 'quality of evidence (GRADE)' section of discussion, contacted the authors of the original studies, edited report, revised and approved the final version. E.C.- - searched and screened trials from PubMed, critically appraised, extracted data and assessed risk of bias of studies, wrote methodology section, did formatting of report, revised and approved the final version. N.N. - searched and screened trials from PubMed, critically appraised extracted data and assessed risk of bias of studies, wrote 'Discussion' (apart from the quality of evidence portion), 'Strengths and Limitations', and 'Supplementary S1-Search Strategies', revised and approved the final version. A.O.-searched/screened Cochrane database, critically appraised studies, extracted data from and assessed risk of bias of studies, bias table and part of the bias report, revised and approved the final version. M.S. - Searched and screened trials from Embase, critically appraised studies, extracted data and assessed risk of bias of studies, co-wrote the results section of report, measured the precision of GetData Digitizer tool \& Supplementary S2, Table S1 and Table S2, revised and approved the final version. R.T.- -searched and screened trials from the Cochrane library, critically appraised studies, extracted data from and assessed risk of bias of studies, wrote the abstract, parts of the bias report and references, revised and approved the final version. G.T.T.Y.searched and screened trials from Medline, critically appraised, extracted data and assessed risk of bias of studies, Introduction and Aims and Objectives sections of report. G.R.-supervised, critically appraised all versions and the results, revised and approved the final version. Z.M.-developed the meta-analysis, critically appraised, revised and approved the final version. P.F.-Conceptualised the review, supervised, critically appraised all versions and the results, coordinated the meta-analysis process, revised and approved the final version. All authors have read and agreed to the published version of the manuscript.

Funding: This research received no external funding.

Institutional Review Board Statement: Not applicable.

Informed Consent Statement: Not applicable.

Data Availability Statement: All the data are included in the manuscript.

Conflicts of Interest: The authors declare no conflict of interest.

\section{References}

1. Scottish Intercollegiate Guidelines Network. Diagnosis and Management of Colorectal Cancer: A National Clinical Guideline. 2016. Available online: https:/ /www.sign.ac.uk/assets/sign126.pdf (accessed on 20 May 2020).

2. Cancer Research UK. Cancer Research UK. Bowel Cancer Statistics. Available online: https://www.cancerresearchuk.org/healthprofessional/cancer-statistics/statistics-by-cancer-type/bowel-cancer\#heading-Zero (accessed on 20 May 2020).

3. National Institute for Health and Care Excellence. Colorectal Cancer: NICE Guideline. 2020. Available online: https:/ /www.nice. org.uk/guidance/ng151/resources/colorectal-cancer-pdf-66141835244485 (accessed on 20 May 2020).

4. Dragovich, T.; Tsikltis, V.L. Medscape. Colon Cancer. Available online: https://emedicine.medscape.com/article/277496 -overview\#a4 (accessed on 20 May 2020). 
5. Mayo Clinic. Mayo Clinic. Colectomy. Available online: https://www.mayoclinic.org/tests-procedures/colectomy/about/pac20384631 (accessed on 20 May 2020).

6. Macmillan Cancer Support. Macmillan Cancer Support. Surgery to Remove Colon Cancer. Available online: https:// www.macmillan.org.uk/cancer-information-and-support/treatments-and-drugs/surgery-to-remove-colon-cancer (accessed on 20 May 2020).

7. National Health Service (NHS). Treatment: Bowel Cancer. Available online: https://www.nhs.uk/conditions/bowel-cancer/ treatment/ (accessed on 20 May 2020).

8. Forget, P.; Simonet, O.; De Kock, M. Cancer surgery induces inflammation, immunosuppression and neo-angiogenesis, but is it influenced by analgesics? F1000Research 2013, 2, 102. [CrossRef]

9. Higgins, J.P.; Green, S. Cochrane Handbook for Systematic Reviews of Interventions; John Wiley \& Sons: Hoboken, NJ, USA, 2011.

10. Moher, D.; Liberati, A.; Tetzlaff, J.; Altaman, D.G. Preferred reporting items for systematic reviews and meta-analyses: The PRISMA statement. PLoS Med. 2009, 6, e1000097. [CrossRef]

11. Tung, K.; Cheung, H.; Ng, L.; Chung, C.; Li, M. Endo-laparoscopic approach versus conventional open surgery in the treat-ment of obstructing left-sided colon cancer: Long-term follow-up of a randomized trial. Asian J. Endosc. Surg. 2013, 6, 78-81. [CrossRef]

12. Braga, M.; Frasson, M.; Vignali, A.; Zuliani, W.; Civelli, V.; Di Carlo, V. Laparoscopic vs. Open Colectomy in Cancer Patients: Long-Term Complications, Quality of Life, and Survival. Dis. Colon Rectum 2005, 48, 2217-2223. [CrossRef]

13. Braga, M.; Frasson, M.; Zuliani, W.; Vignali, A.; Pecorelli, N.; Di Carlo, V. Randomized clinical trial of laparoscopic versus open left colonic resection. BJS 2010, 97, 1180-1186. [CrossRef]

14. Chung, C.C.; Ng, D.; Tsang, W.W.C.; Tang, W.L.; Yau, K.K.K.; Cheung, H.Y.S.; Wong, J.C.H.; Li, M.K.W. Hand-assisted Laparoscopic Versus Open Right Colectomy. Ann. Surg. 2007, 246, 728-733. [CrossRef] [PubMed]

15. Fleshman, J.; Sargent, D.; Green, E.; Anvari, M.; Stryker, S.J.; Beart, R.W.; Hellinger, M.; Flanagan, R.; Peters, W.; Nelson, H. Laparoscopic Colectomy for Cancer Is Not Inferior to Open Surgery Based on 5-Year Data from the COST Study Group Trial. Ann. Surg. 2007, 246, 655-664. [CrossRef] [PubMed]

16. 1Kitano, S.; Inomata, I.; Mizusawa, J.; Katayama, H.; Watanabe, M.; Yamamoto, S. Survival outcomes following laparoscopic versus open D3 dissection for stage II or III colon cancer (JCOG0404): A phase 3, randomised controlled trial. Lancet Gastroenterol. Hepatol. 2017, 2, 261-268. [CrossRef]

17. Ishibe, A.; Ota, M.; Fujii, S.; Suwa, Y.; Suzuki, S.; Suwa, H.; Momiyama, M.; Watanabe, J.; Watanabe, K.; Taguri, M.; et al. Midterm follow-up of a randomized trial of open surgery versus laparoscopic surgery in elderly patients with colorectal cancer. Surg. Endosc. 2017, 31, 3890-3897. [CrossRef] [PubMed]

18. Li, J.C.-M.; Leung, K.L.; Ng, S.S.-M.; Liu, S.Y.-W.; Lee, J.F.-Y.; Hon, S.S.-F. Laparoscopic-assisted versus open resection of right-sided colonic cancer-A prospective randomized controlled trial. Int. J. Color. Dis. 2011, 27, 95-102. [CrossRef] [PubMed]

19. The Colon Cancer Laparoscopic or Open Resection Study Group. Survival after laparoscopic surgery versus open surgery for colon cancer: Long-term outcome of a randomised clinical trial. Lancet Oncol. 2009, 10, 44-52. [CrossRef]

20. Toritani, K.; Watanabe, J.; Nakagawa, K.; Suwa, Y.; Suwa, H.; Ishibe, A. Randomized controlled trial to evaluate laparoscopic versus open surgery in transverse and descending colon cancer patients. Int. J. Colorectal Dis. 2019, 34, 1211-1220. [CrossRef]

21. GetData Graph Digitizer-Graph Digitizing Software. Getdata-Graph-Digitizer.com. Available online: http://getdata-graphdigitizer.com/ (accessed on 17 May 2020).

22. GRADE Working Group. Handbook for Grading the Quality of Evidence and the Strength of Recommendations Using the GRADE Approach (Updated October 2013); Chünemann, H., Brożek, J., Guyatt, G., Oxman, A., Eds.; GRADE [Chapter 12.2.1]; The Cochrane Collaboration: London, UK, 2013. Available online: http://gdt.guidelinedevelopment.org/app/handbook/handbook.html (accessed on 20 May 2020).

23. Chapter 7: Considering bias and conflicts of interest among the included studies. In Cochrane Handbook for Systematic Reviews of Interventions Version 6.1 (Updated September 2020); Higgins, J.P.T.; Thomas, J.; Chandler, J.; Cumpston, M.; Li, T.; Page, M.J.; Welch, V.A. (Eds.) Cochrane: London, UK, 2020. Available online: https:/ / www.training.cochrane.org/handbook (accessed on 20 May 2020).

24. Chapter 6: Choosing effect measures and computing estimates of effect. In Cochrane Handbook for Systematic Reviews of Interventions Version 6.1 (Updated September 2020); Higgins, J.P.T.; Thomas, J.; Chandler, J.; Cumpston, M.; Li, T.; Page, M.J.; Welch, V.A. (Eds.) Cochrane: London, UK, 2020. Available online: https:/ / www.training.cochrane.org/handbook (accessed on 20 May 2020).

25. Scottish Intercollegiate Guidelines Network (SIGN). Critical Appraisal Notes and Checklists. Available online: https://www. sign.ac.uk/checklists-and-notes.html (accessed on 15 May 2020).

26. Dumville, J.C.; Torgerson, D.; Hewitt, C.E. Reporting attrition in randomised controlled trials. BMJ 2006, 332, 969-971. [CrossRef]

27. Guner, A.; Kim, H.-I. Biomarkers for Evaluating the Inflammation Status in Patients with Cancer. J. Gastric Cancer 2019, 19, 254-277. [CrossRef] [PubMed]

28. Behrenbruch, C.; Shembrey, C.; Paquet-Fifield, S.; Mølck, C.; Cho, H.-J.; Michael, M.; Thomson, B.N.J.; Heriot, A.G.; Hollande, F. Surgical stress response and promotion of metastasis in colorectal cancer: A complex and heterogeneous process. Clin. Exp. Metastasis 2018, 35, 333-345. [CrossRef] [PubMed]

29. Forget, P.; Aguirre, J.A.; Bencic, I.; Borgeat, A.; Cama, A.; Condron, C.; Eintrei, C.; Eroles, P.; Gupta, A.; Hales, T.G.; et al. How Anesthetic, Analgesic and Other Non-Surgical Techniques During Cancer Surgery Might Affect Postoperative Oncologic Outcomes: A Summary of Current State of Evidence. Cancers 2019, 11, 592. [CrossRef] [PubMed] 
30. Mallat, J. Understanding the null hypothesis (H0) in non-inferiority trials. Crit. Care 2017, 21, 101. [CrossRef]

31. Case, L.D.; Ambrosius, W.T. Power and Sample Size. Methods Mol. Biol. 2007, 404, 377-408. [CrossRef]

32. Day, R. Comorbidities in Older People. GP Online. 2017. Available online: https://www.gponline.com/comorbidities-olderpeople/elderly-care/article/1440520 (accessed on 18 May 2020).

33. Søgaard, M.; Thomsen, R.; Bossen, K.S.; Sørensen, H.H.T.; Nørgaard, M. The impact of comorbidity on cancer survival: A review. Clin. Epidemiology 2013, 5, 3-29. [CrossRef]

34. Sterne, J.A.C.; Savović, J.; Page, M.J.; Elbers, R.G.; Blencowe, N.S.; Boutron, I.; Cates, C.J.; Cheng, H.-Y.; Corbett, M.S.; Eldridge, S.M.; et al. RoB 2: A revised tool for assessing risk of bias in randomised trials. BMJ 2019, 366, 14898. [CrossRef] [PubMed]

35. Di, B.; Li, Y.; Wei, K.; Xiao, X.; Shi, J.; Zhang, Y.; Yang, X.; Gao, P.; Zhang, K.; Yuan, Y.; et al. Laparoscopic versus open surgery for colon cancer: A meta-analysis of 5-year follow-up outcomes. Surg. Oncol. 2013, 22, e39-e43. [CrossRef] [PubMed]

36. Song, X.-J.; Liu, Z.-L.; Zeng, R.; Ye, W.; Liu, C.-W. A meta-analysis of laparoscopic surgery versus conventional open surgery in the treatment of colorectal cancer. Medicine 2019, 98, e15347. [CrossRef] [PubMed]

37. Zhang, C.; Zhang, C.; Wang, Q.; Li, Z.; Lin, J.; Wang, H. Differences in Stage of Cancer at Diagnosis, Treatment, and Survival by Race and Ethnicity Among Leading Cancer Types. JAMA Netw. Open 2020, 3, e202950. [CrossRef] [PubMed]

38. Kishore, J.; Goel, M.; Khanna, P. Understanding survival analysis: Kaplan-Meier estimate. Int. J. Ayurveda Res. 2010, 1, $274-278$. [CrossRef]

39. Hackshaw, A. Small studies: Strengths and limitations. Eur. Respir. J. 2008, 32, 1141-1143. [CrossRef] 